\title{
Correction to: Parental high-fat high-sugar diet programming and hypothalamus adipose tissue axis in male Wistar rats
}

\author{
Helena César ${ }^{1}$. Marcela Nascimento Sertorio ${ }^{2}$. Esther Alves de Souza ${ }^{2} \cdot$ Giovana Jamar $^{3} \cdot$ Aline Santamarina $^{3}$. \\ Andrea Jucá $^{3}$ - Débora Estadella ${ }^{3}$ (1) $\cdot$ Breno Picin Casagrande ${ }^{3} \cdot$ Luciana Pellegrini Pisani $^{3}$ (1)
}

Published online: 8 November 2021

(c) The Author(s), under exclusive licence to Springer-Verlag GmbH Germany 2021

\section{Correction to: European Journal of Nutrition} https://doi.org/10.1007/s00394-021-02690-1

Unfortunately, author name was missing in the original version of the article. The missing author name and affiliation are given below:

Débora Estadella

Departamento de Biociências, Universidade Federal de São Paulo, Santos (SP), Brazil.

The original article can be found online at https://doi.org/10.1007/ s00394-021-02690-1.

Luciana Pellegrini Pisani

lucianapisani@gmail.com

1 Programa de Pós-Graduação Interdisciplinar em Ciências da Saúde, Universidade Federal de São Paulo-UNIFESP, Santos, SP, Brazil

2 Programa de Pós-Graduação em Nutrição, Universidade Federal de São Paulo, São Paulo, SP, Brazil

3 Departamento de Biociências, Universidade Federal de São Paulo, Silva Jardim, 136. Laboratório 311, $3^{\circ}$ andar, Vila Mathias, Santos, SP 11015-020, Brazil 